\title{
Electrochemical Mechanism of Recovery of Nickel Metal from Waste Lithium Ion Batteries by Molten Salt Electrolysis
}

\author{
Hui Li, Yutian Fu, Jinglong Liang *, Chenxiao Li, Jing Wang, Hongyan Yan and Zongying Cai
}

check for

updates

Citation: Li, H.; Fu, Y.; Liang, J.; Li, C.; Wang, J.; Yan, H.; Cai, Z.

\section{Electrochemical Mechanism of}

Recovery of Nickel Metal from Waste Lithium Ion Batteries by Molten Salt Electrolysis. Materials 2021, 14, 6875. https://doi.org/10.3390/ma14226875

Academic Editors: Olga Rodríguez

Largo, Piotr Piszczek and

Aleksandra Radtke

Received: 31 August 2021

Accepted: 11 November 2021

Published: 15 November 2021

Publisher's Note: MDPI stays neutral with regard to jurisdictional claims in published maps and institutional affiliations.

Copyright: (c) 2021 by the authors. Licensee MDPI, Basel, Switzerland. This article is an open access article distributed under the terms and conditions of the Creative Commons Attribution (CC BY) license (https:/ / creativecommons.org/licenses/by/ $4.0 /)$.
College of Metallurgy and Energy, North China University of Science and Technology, Tangshan 063210, China; lh@ncst.edu.cn (H.L.); fu1849759929@163.com (Y.F.); lichenxiao@ncst.edu.cn (C.L.); xongmao9786@163.com (J.W.); yanhy@ncst.edu.cn (H.Y.); caizy@ncst.edu.cn (Z.C.)

* Correspondence: lj1@ncst.edu.cn

\begin{abstract}
With the widespread use of lithium-ion batteries, the cumulative amount of used lithiumion batteries is also increasing year by year. Since waste lithium-ion batteries contain a large amount of valuable metals, the recovery of valuable metals has become one of the current research hotspots. The research uses electrometallurgical technology, and the main methods used are cyclic voltammetry, square wave voltammetry, chronoamperometry and open circuit potential. The electrochemical reduction behavior of $\mathrm{Ni}^{3+}$ in $\mathrm{NaCl}-\mathrm{CaCl}_{2}$ molten salt was studied, and the electrochemical reduction behavior was further verified by using a Mo cavity electrode. It is determined that the reduction process of $\mathrm{Ni}^{3+}$ in $\mathrm{LiNiO}_{2}$ is mainly divided into two steps: $\mathrm{LiNiO}_{2} \rightarrow \mathrm{NiO} \rightarrow \mathrm{Ni}$. Through the analysis of electrolysis products under different conditions, when the current value of $\mathrm{LiNiO}_{2}$ is not less than $0.03 \mathrm{~A}$, the electrolysis product after $10 \mathrm{~h}$ is metallic Ni. When the current reaches $0.07 \mathrm{~A}$, the current efficiency is $77.9 \%$, while the $\mathrm{Li}^{+}$in $\mathrm{LiNiO}_{2}$ is enriched in $\mathrm{NaCl}-\mathrm{CaCl}_{2}$ molten salt. The method realizes the separation and extraction of the valuable metal $\mathrm{Ni}$ in the waste lithium-ion battery.
\end{abstract}

Keywords: used lithium-ion batteries; recycling nickel; electrochemical reduction; constant current electrolysis

\section{Introduction}

China's primary metal resources are gradually diminishing [1,2]. The recovery of valuable metals in waste lithium-ion batteries has major significance for the comprehensive utilization of waste resources [3,4].

Previous studies mainly adopted hydrometallurgical technology [5-11], which realized the recovery and utilization of $\mathrm{Ni}$ and other valuable metals through leaching, roasting and other processes. Although the method has a higher metal recovery and lower energy consumption, the entire process requires excessive acid-base solution and produces too much waste. Based on wet technology, the biological leaching method [12,13] has problems such as a long cycle and harsh microbial culture conditions. At present, molten salt electrolysis technology continues to develop, mainly through electro-chemical methods to control the reduction process to prepare metals or alloys.

Chen et al. [14-18] used $\mathrm{CaCl}_{2}$ melt to directly reduce $\mathrm{TiO}_{2}, \mathrm{NiO}, \mathrm{TiO}, \mathrm{ZrO}, \mathrm{Tb}_{4} \mathrm{O}_{7}$, $\mathrm{Fe}_{2} \mathrm{O}_{3}$, etc., using a solid oxide or a mixture of two solid oxides as raw materials. The corresponding Ti metal, $\mathrm{Cr}$ metal, TiNi alloy, TiZr alloy and $\mathrm{TbFe}_{2}$ alloy were prepared, and the solid $\mathrm{Cr}_{2} \mathrm{O}_{3}$ electrolysis process was optimized in $\mathrm{CaCl}_{2}$ and $\mathrm{NaCl}-\mathrm{CaCl}_{2}$ molten salt [19]. The feasibility of the melt's electrolysis process in the preparation of metals or alloys has been confirmed in the above studies. For the extraction of valuable metals from waste lithium ions, Yin Huayi et al. [20] used $\mathrm{Na}_{2} \mathrm{CO}_{3}-\mathrm{K}_{2} \mathrm{CO}_{3}$ molten salt to successfully prepare $\mathrm{Li}$ and $\mathrm{Co}$ through the electrolysis of $\mathrm{LiCoO}_{2}$. Compared with hydrometallurgy, the molten salt electrolysis process does not use a strong acid solution, so it will not produce too much waste. At the same time, compared with large-scale and large-emission 
pyrometallurgy, molten salt electrolysis does not use reducing agents, so the cost is lower, the exhaust gas emissions are small, and it is environmentally friendly [20,21].

The NaCl-CaCl 2 molten salt was selected to study the electrolysis behavior of $\mathrm{LiNiO}_{2}$. Using electrochemical testing methods of cyclic voltammetry, square wave voltammetry, chronoamperometry and open circuit potential, the reduction mechanism of $\mathrm{LiNiO}_{2}$ in the electrolysis process was analyzed, and metal Ni was successfully prepared by constant current electrolysis. The products at different stages in the reduction process were analyzed and the optimal reduction conditions were determined. The recycling process is simple, easy to operate, high in efficiency and does not introduce other impurities, and provides a new idea for the recycling of precious metals in waste lithium ion batteries.

\section{Experimental Method}

The electrochemical test was carried out using a three-electrode system. The platinum wire placed in the alumina tube $(\Phi=4 \mathrm{~mm})$ was used as the reference electrode, the Mo cavity hole electrode $(2 \mathrm{~mm} \times 1 \mathrm{~mm} \times 30 \mathrm{~mm})$ was used as the working electrode and the high-purity graphite sheet $(99.99 \%, 20 \mathrm{~mm} \times 5 \mathrm{~mm} \times 100 \mathrm{~mm})$ as the auxiliary electrode. First, the pure salt $\left(\mathrm{NaCl}, \mathrm{CaCl}_{2}\right)$ was placed in a DZF-6020 vacuum drying oven (Boxun, Shanghai, China), dried at a constant temperature of $220^{\circ} \mathrm{C}$ for $600 \mathrm{~min}$ and weighed $150 \mathrm{~g}$ with a molar ratio of $\mathrm{n}_{\mathrm{NaCl}}: \mathrm{n}_{\mathrm{CaCl} 2}=1: 1$; it was then crushed and mixed evenly, and put into the corundum crucible. Then, the mixed salt was put in a vacuum drying oven and removed after drying at $250{ }^{\circ} \mathrm{C}$ for $12 \mathrm{~h}$. The dried mixed salt was placed in a resistance heating furnace (Yunjie, Baotou, China) heated at $5^{\circ} \mathrm{C} / \mathrm{min}$ to $750{ }^{\circ} \mathrm{C}$, then kept at a constant temperature for $120 \mathrm{~min}$, and argon gas was passed through the entire process for protection. Next, the electrodes were inserted into the molten salt to test the electrochemical behavior of the Mo working electrode and the Mo cavity electrode. Then, $2 \mathrm{~g}$ of the $\mathrm{LiNiO}_{2}$ and $\mathrm{Mo}$ cavity electrode filled with $\mathrm{LiNiO}_{2}$ were respectively added to the melts, kept at a constant temperature for $240 \mathrm{~min}$, and the three-electrode electrochemical test was performed again.

The electrolysis experiment was carried out with a two-electrode system. The $0.7 \mathrm{~g}$ sintered $\mathrm{LiNiO}_{2}$ flakes (about $15 \mathrm{~mm}$ in diameter and about $1 \mathrm{~mm}$ in thickness) were tightly wrapped with stainless steel mesh, and then fixed on a stainless steel rod as a cathode. High-purity graphite flakes $(99.99 \%, 20 \mathrm{~mm} \times 5 \mathrm{~mm} \times 100 \mathrm{~mm})$ were fixed on another stainless steel rod as an auxiliary electrode. The two electrodes were placed in the $\mathrm{NaCl}-\mathrm{CaCl}_{2}$ molten salt at $750{ }^{\circ} \mathrm{C}$; the electrolysis current range was $0.01-0.15 \mathrm{~A}$ and the electrolysis time was 0-10 h. After the electrolysis, the product was quenched and cleaned, and the sample was tested after drying.

The electrochemical test used Chenhua CHI660E (Chenhua, Shanghai, China) electrochemical workstation, and the Noran7X-ray diffractometer (Rigaku, Tokyo, Japan) was used to analyze the product.

\section{Experimental Results and Discussion}

\subsection{The Electrochemical Behavior of $\mathrm{Ni}^{3+}$ on Mo Electrode}

\subsubsection{Cyclic Voltammetry}

Figure 1 shows the cyclic voltammetry test results of $\mathrm{NaCl}-\mathrm{CaCl}_{2}$ molten salt and $\mathrm{NaCl}-\mathrm{CaCl}_{2}-\mathrm{LiNiO}_{2}$ molten salt when the scanning speed is $0.25 \mathrm{~V} / \mathrm{s}$. The dotted line in the figure is the cyclic voltammetry curve of $\mathrm{NaCl}-\mathrm{CaCl}_{2}$ molten salt. It can be seen that there are only the reduction peaks of $\mathrm{Ca}^{2+}$ and $\mathrm{Na}^{+}$and the oxidation peaks of $\mathrm{Ca}$ and $\mathrm{Na}$, indicating that the $\mathrm{NaCl}-\mathrm{CaCl}_{2}$ molten salt system is between $-1.68 \mathrm{~V}$ and $0.37 \mathrm{~V}$. No oxidation-reduction reaction occurs, and this range can be used as the scanning range after adding $\mathrm{LiNiO}_{2}$ to the $\mathrm{NaCl}-\mathrm{CaCl}_{2}$ molten salt. 


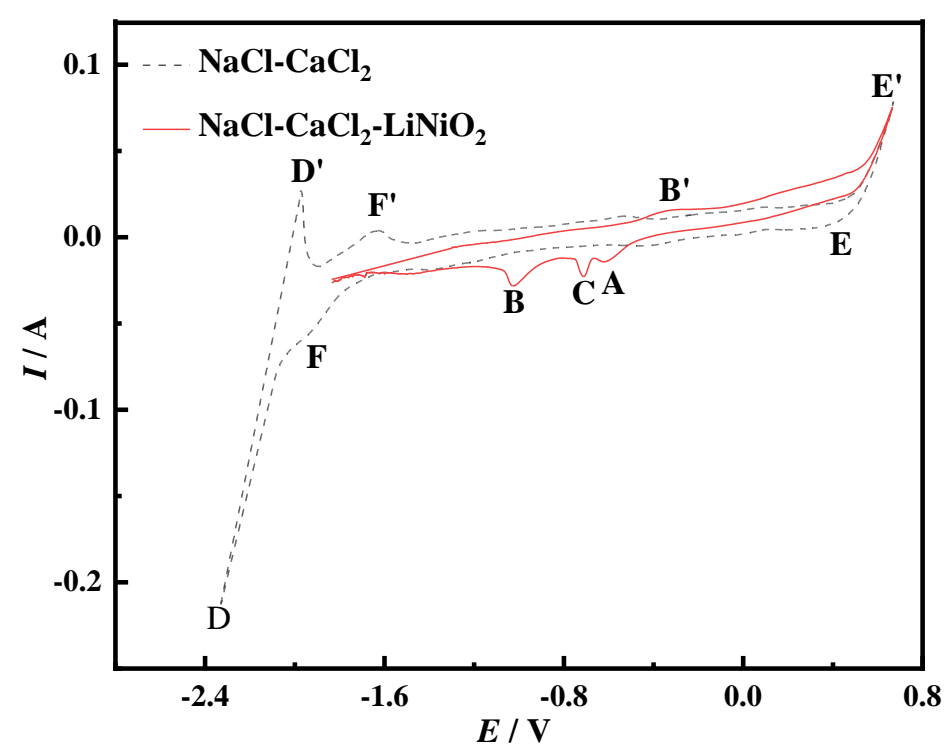

Figure 1. Cyclic voltammogram of Mo electrode before and after adding $\mathrm{LiNiO}_{2}$ to $\mathrm{NaCl}-\mathrm{CaCl}_{2}$ molten salt (scanning speed: $0.25 \mathrm{~V} / \mathrm{s}, \mathrm{T}=750^{\circ} \mathrm{C}$, reference electrode: Pt electrode).

The theoretical decomposition voltages of $\mathrm{NaCl}$ and $\mathrm{CaCl}_{2}$ at $1023 \mathrm{~K}$ are calculated from the data obtained from HSC Chemistry6.0 thermodynamic calculation software (Outokumpu, Finland). The theoretical decomposition voltages are $-3.238 \mathrm{~V}$ and $-3.325 \mathrm{~V}$, respectively. Since the theoretical decomposition voltage difference between the two is relatively small, peak $\mathrm{D}$ and peak $\mathrm{D}^{\prime}$ are the overlapping reduction peak and oxidation peak of $\mathrm{Na}$ and $\mathrm{Ca}$, respectively. Since $\mathrm{Na}$ is volatile, the peak $\mathrm{D}^{\prime}$ is smaller than the reduced peak $\mathrm{D}$. Since $\mathrm{CaCl}_{2}$ also has a certain degree of water absorption in molten salt, the formation of $\mathrm{CaO}$ causes the peak $\mathrm{F}$ to be relatively gentle. The formation of the peak $\mathrm{F}^{\prime}$ is mainly due to the oxidation of the elemental Ca [22]. Peak $\mathrm{E}^{\prime}$ corresponds to the oxidation of $\mathrm{Cl}^{-}$. The generation of $\mathrm{Cl}_{2}$ changes the ion concentration around the molten salt and increases the reduction rate. The increase in the reduction rate increases the current to form peak E. The cyclic voltammetry curve shown by the solid line in the figure has multiple peaks, indicating that the electrochemical process of $\mathrm{Ni}^{3+}$ on the Mo electrode is a multi-step reduction process.

Konishi et al. [23] studied the process of preparing Fe-Dy alloy thin films by the molten salt electrochemical method. In this process, iron and dysprosium can form alloys. It can be seen from the electrochemical cyclic voltammetry curve that the reduction peak potential during the reaction is more positive than the deposition potential of dysprosium metal, so this peak is considered as an alloy peak. Kubota et al. [24] studied the formation mechanism of Co-Gd alloy films by regulating the electrochemical reaction process of molten salt. Since cobalt and gadolinium can form an alloy, it is judged that the peak corresponding to the reduction current in the cyclic voltammetry curve is the alloy peak. The objects of this study, Ni and Mo, will also form an alloy. When using a Mo electrode, there are three reduction peaks in the cyclic voltammetry curve of Ni. The peak potential of peak $\mathrm{A}$ is more positive than the deposition potential of $\mathrm{Ni}^{3+}$. It is judged that peak $\mathrm{A}$ is an alloy peak based on literature; there is no electron transfer and metal ion reduction in the process. Therefore, the reduction process of $\mathrm{Ni}^{3+}$ when using a Mo electrode is a two-step reduction.

The cyclic voltammetry curve results of the Mo electrode measured at different sweep speeds in the $\mathrm{NaCl}-\mathrm{CaCl}_{2}-\mathrm{LiNiO}_{2}$ system at $750{ }^{\circ} \mathrm{C}$ are shown in Figure 2. Under certain sweep speed conditions, when the potential reverse scanning process reaches the first chemical reaction reduction potential, the current gradually increases with the change in the potential. With the continuous negative shift of the scanning potential, $\mathrm{Ni}^{3+}$ is gradually 
enriched at the cathode. In this process, the charge transfer speed is slow, which causes the current to not continue to increase, and finally forms the limiting current.

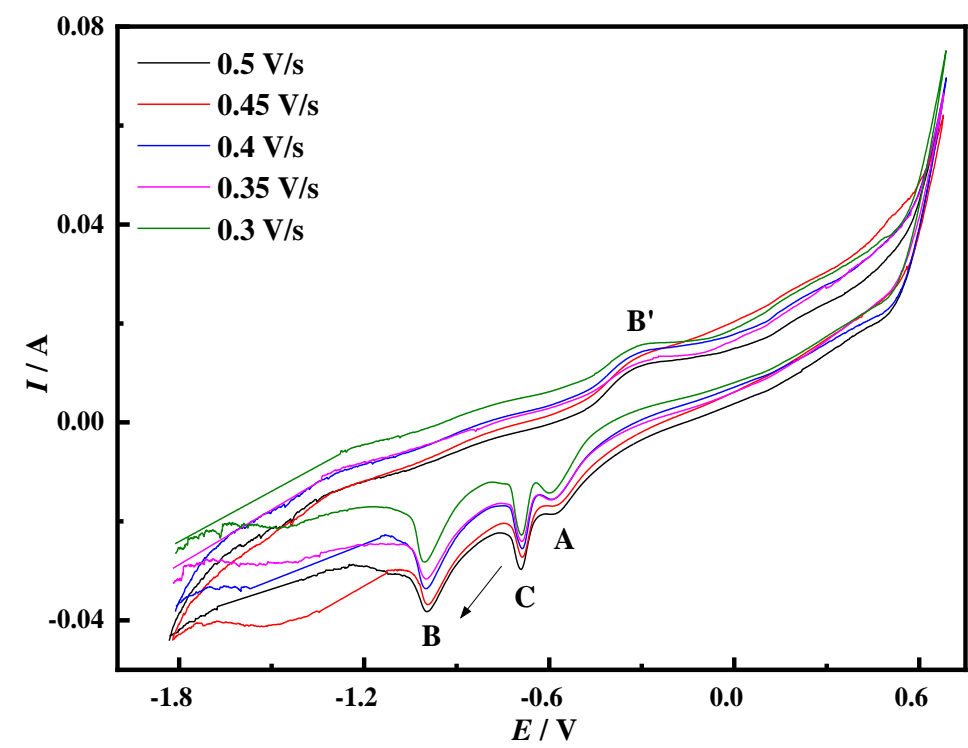

Figure 2. Cyclic voltammogram on $\mathrm{Mo}$ electrode in $\mathrm{NaCl}-\mathrm{CaCl}_{2}-\mathrm{LiNiO}_{2}$ system (Scan speed: $0.3-0.5 \mathrm{~V} / \mathrm{s}, \mathrm{T}=750{ }^{\circ} \mathrm{C}$, reference electrode: Pt electrode).

As the electrochemical reaction progresses, the reduction products at the cathode diffuse into the molten salt slowly, occupying the reduction sites at the cathode. The lower concentration of reactive ions reduces the number of charge transfers and reduces the current, eventually forming peak $C$. The electrolysis process is mainly controlled by diffusion. When the reduction potential of the second chemical reaction is reached, the reduction process changes from the charge transfer process to the diffusion process, and peak B is formed. During the forward sweep of the potential, the Ni elemental substance is re-oxidized to form the peak $B^{\prime}$. It can be seen from Figure 2 that the peak potentials $E_{p c}$ and $E_{p a}$ of peaks $\mathrm{B}$ and $\mathrm{B}^{\prime}$ are affected by the scanning speed $v$. The increase in the scanning speed makes the electrochemical reaction speed faster, promotes the rapid transfer of electric charge and increases the limiting current.

The $\mathrm{Ni}^{2+}$ in the molten salt is transported to the surface of the cathode through liquid phase mass transfer, and electrons are obtained between the two-phase interface of the cathode and the molten salt and, finally, metallic Ni is formed on the surface of the cathode. In the above process, the formation speed of metal Ni is faster, and the speed of mass transfer and electron transfer is slow, which leads to the phenomenon of electrode polarization. This phenomenon causes the electrode potential to move in a direction deviating from the equilibrium potential, which is manifested in that the peak potential of peak B moves in the negative direction, and the peak potential of peak $\mathrm{B}^{\prime}$ moves in the positive direction. According to the characteristics of the cyclic voltammetry curve of peak $\mathrm{B}$, it is judged that peak B corresponds to a quasi-reversible reaction. The peak current of peak $C$ increases with the increase in the scanning speed, there is no corresponding oxidation peak and the electrode reaction is judged to be an irreversible reaction.

In order to judge the control steps of the electrochemical reaction process, the $i_{p c}-v^{1 / 2}$ and $E_{p c}-v^{1 / 2}$ curves of peak $C$ and peak $B$ are drawn according to Figure 2, as shown in Figure 3 . The current density value $i_{p c}$ of peak $C$ has a linear relationship with the square root of the scan rate $v^{1 / 2}$, and this process is mainly controlled by diffusion transfer. The current density value $i_{p c}$ and peak potential of peak B are linearly related to the square root of the scan rate $v^{1 / 2}$, and the process is jointly controlled by diffusion and electron transfer. 

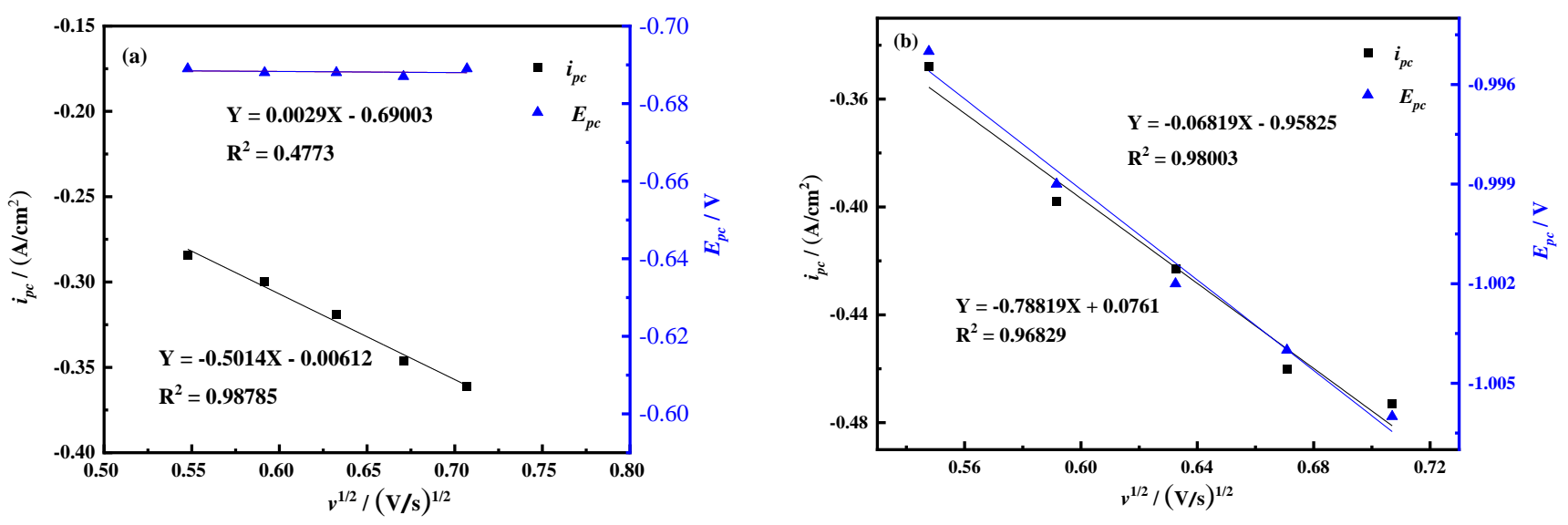

Figure 3. Curves of reduced peaks $i_{p c} v^{1 / 2}$ and $E_{p c}-v^{1 / 2}(\mathbf{a})$ Peak C (b) Peak B $\left(\mathrm{A}=0.08046 \mathrm{~cm}^{2}\right)$.

\subsubsection{Square Wave Voltammetry}

In order to study the electrochemical reduction behavior of $\mathrm{Ni}^{3+}$ in the $\mathrm{NaCl}-\mathrm{CaCl}_{2}-$ $\mathrm{LiNiO}_{2}$ molten salt system, the square wave voltammetry with higher resolution and sensitivity was used to measure at different frequencies. This method can effectively suppress the capacitive background current that often occurs in cyclic voltammetry at relatively high scanning speeds. The selected test temperature is $750{ }^{\circ} \mathrm{C}$, and the frequency is $10-30 \mathrm{~Hz}$. The curve is shown in Figure 4.

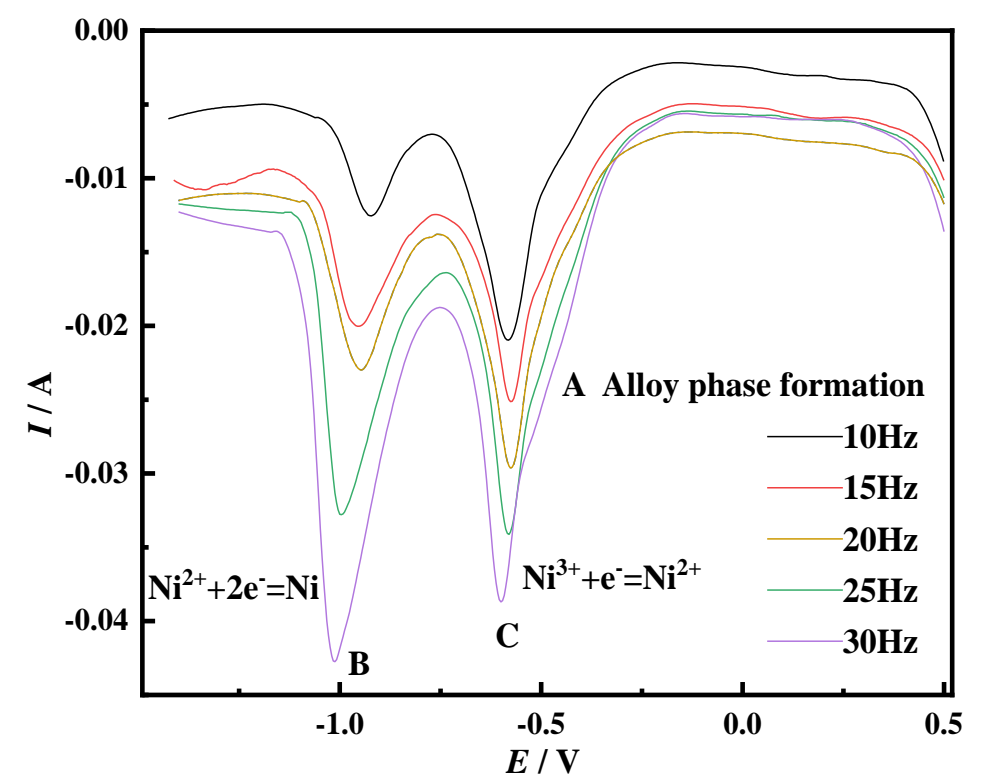

Figure 4. SWV diagram of the Mo electrode in the $\mathrm{NaCl}-\mathrm{CaCl}_{2}-\mathrm{LiNiO}_{2}$ system $(f: 10-30 \mathrm{~Hz}$, $T=750{ }^{\circ} \mathrm{C}$, reference electrode: Pt electrode, area $=0.08046 \mathrm{~cm}^{2}$ ).

There are three peaks A, C and B in the square wave voltammetry curve, and peak A is the alloy peak. The presence of peaks $\mathrm{B}$ and $\mathrm{C}$ indicates that $\mathrm{Ni}^{3+}$ forms a Ni elementary substance through a two-step electrochemical reduction process, which is consistent with the results of the cyclic voltammetry test.

In the square wave volt-ampere curve, the relationship between the half-width $W_{1 / 2}$ and the number of transferred electrons $n$ is expressed by Formula (1).

$$
W_{1 / 2}=3.52 \times \frac{R T}{n F}
$$


In the formula: $\mathrm{R}$-molar gas constant $(8.3145 \mathrm{~J} / \mathrm{mol} / \mathrm{K}), T$-temperature $(\mathrm{K}), n$-electron transfer number, $F$-Faraday's constant $(96,485 \mathrm{C} / \mathrm{mol})$.

Generally speaking, this method is only effective for reversible reactions, and the reversibility can be judged by the linear relationship between the square root of frequency and the peak current density. Draw the relationship between the peak current density and the square root of frequency according to the square wave volt-ampere data in Figure 4, as shown in Figure 5 . It can be seen from the figure that for peak $\mathrm{B}, i_{p c}, E_{p c}$ and $f^{1 / 2}$ are linear, but for peak $C, E_{p c}$ and $f^{1 / 2}$ are not linear. At the same time, it is judged that the electrochemical reduction process corresponding to this peak is irreversible, so the number of transferred electrons can be calculated for peak B by Formula (1).
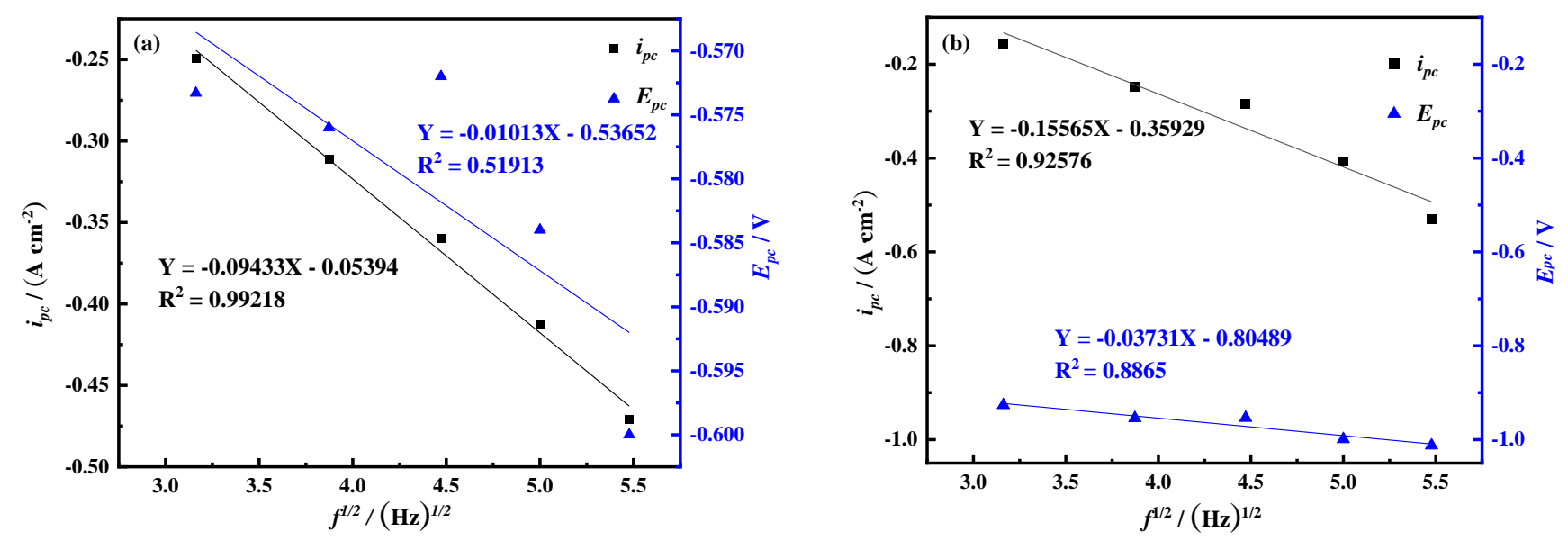

Figure 5. Curves of reduced peaks $i_{p c}-f^{1 / 2}$ and $E_{p c}-f^{1 / 2}(\mathbf{a})$ peak $C(\mathbf{b})$ peak B.

Peak B was fitted according to the square wave voltammetry, as shown in Figure 6. The half-width of peak $B$ is $W_{1 / 2}=0.15$, and the number of electrons transferred from peak $\mathrm{B}$ is $n=2.06$, calculated from Formula (1), which is about equal to $n=2$, and the number of electrons transferred from peak $\mathrm{C}$ is judged to be 1 . Therefore, the reaction of $\mathrm{Ni}^{3+}$ on the Mo electrode is shown in Equations (2) and (3):

$$
\begin{gathered}
\text { Peak A: } \mathrm{Ni}^{3+}+\mathrm{e}^{-}=\mathrm{Ni}^{2+} \\
\text { Peak B: } \mathrm{Ni}^{2+}+\mathrm{e}^{-}=\mathrm{Ni}
\end{gathered}
$$

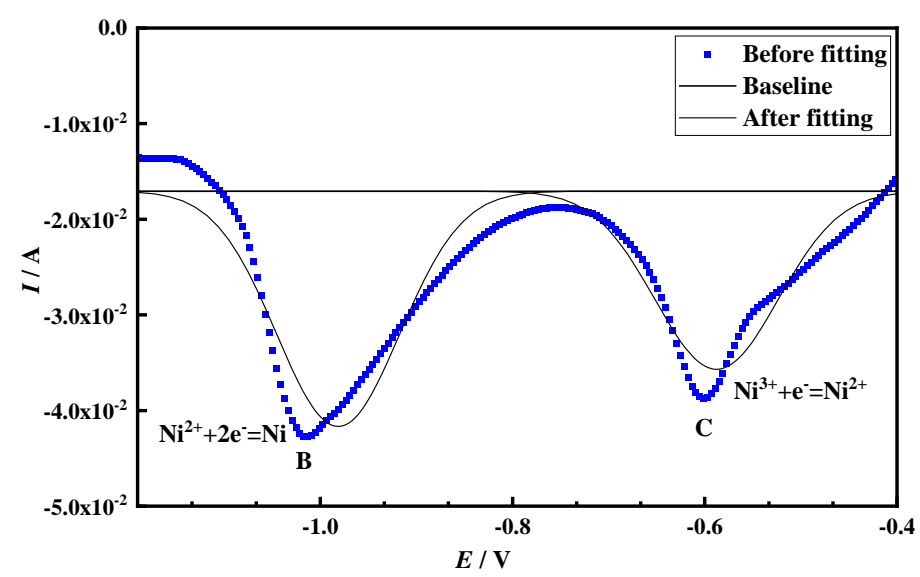

Figure 6. Peak shape fitting diagram of square wave voltammogram of $\mathrm{LiNiO}_{2}$ in $\mathrm{NaCl}-\mathrm{CaCl}_{2}$ molten salt under $30 \mathrm{~Hz}$ condition. 
It can be seen from the above analysis that the electrochemical reduction process of $\mathrm{Ni}^{3+}$ on the Mo electrode is divided into two steps, which is consistent with the results of the cyclic voltammetry curve test.

\subsubsection{Chronoamperometry}

Figure 7 shows the $I-t$ curve of the Mo electrode in the molten salt system of $\mathrm{NaCl}$ $\mathrm{CaCl}_{2}-\mathrm{LiNiO}_{2}$ at $750{ }^{\circ} \mathrm{C}$ under different potential tests. Due to the electric double layer charging behavior between the electrode and the electrolyte, the initial current value in the figure is relatively large. Under different potential conditions, the initial current is proportional to the potential.

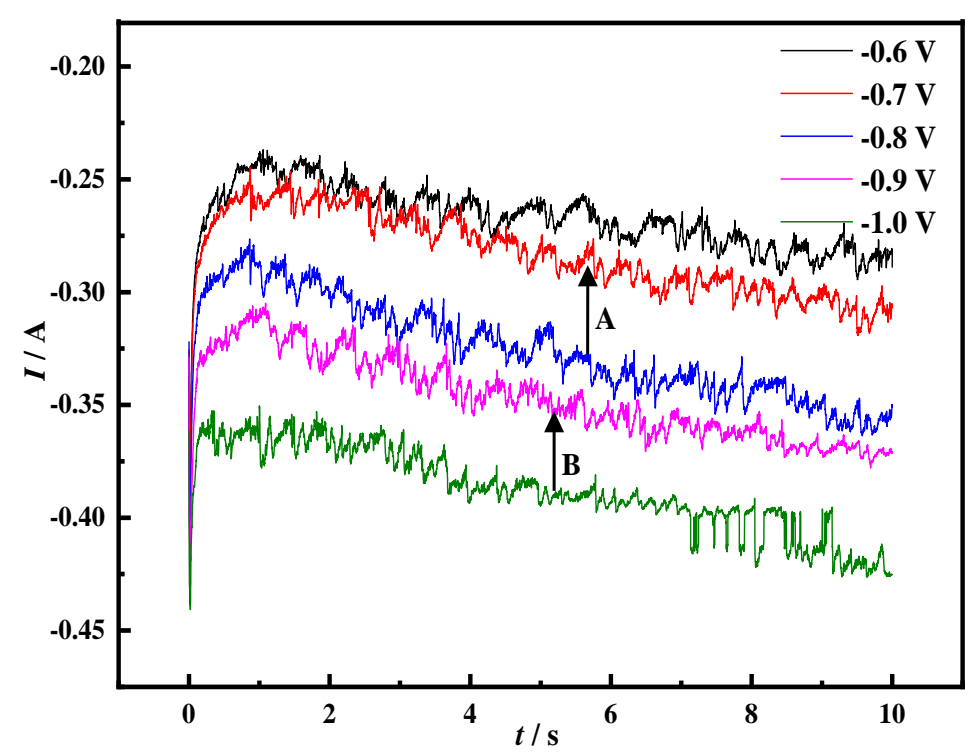

Figure 7. Cyclic voltammetry curve of $\mathrm{Mo}$ electrode in $\mathrm{NaCl}-\mathrm{CaCl}_{2}-\mathrm{LiNiO}_{2}$ molten salt system (scanning speed: $-0.6--1.0 \mathrm{~V} / \mathrm{s}, \mathrm{T}=750^{\circ} \mathrm{C}$, reference electrode: $\mathrm{Pt}$ electrode).

In the potential range of $-0.6--0.7 \mathrm{~V}$, no obvious potential transition occurs. The current step $\mathrm{A}$ at $-0.8 \mathrm{~V}$ indicates that $\mathrm{Ni}^{3+}$ has electrochemical reduction behavior in the potential range of $-0.7--0.8 \mathrm{~V}$, corresponding to the reduction step of $\mathrm{Ni}^{3+} \rightarrow \mathrm{Ni}^{2+}$. With the change in potential, the current step $\mathrm{B}$ at $-1.0 \mathrm{~V}$ indicates that $\mathrm{Ni}^{2+}$ has electrochemical reduction behavior in the range of $-0.9--1.0 \mathrm{~V}$, corresponding to the reduction step of $\mathrm{Ni}^{2+} \rightarrow \mathrm{Ni}$.

\subsubsection{Open Circuit Chronopotentiometry}

In order to further study the electrochemical reduction behavior of $\mathrm{Ni}^{3+}$ on the $\mathrm{Mo}$ electrode in the $\mathrm{NaCl}-\mathrm{CaCl}_{2}-\mathrm{LiNiO}_{2}$ molten salt system, the open-circuit chronopotentiometry was used for determination. This method records the potential difference between the working electrode and the reference electrode after the electrode is charged for a short period of time, and the result is shown in Figure 8. 


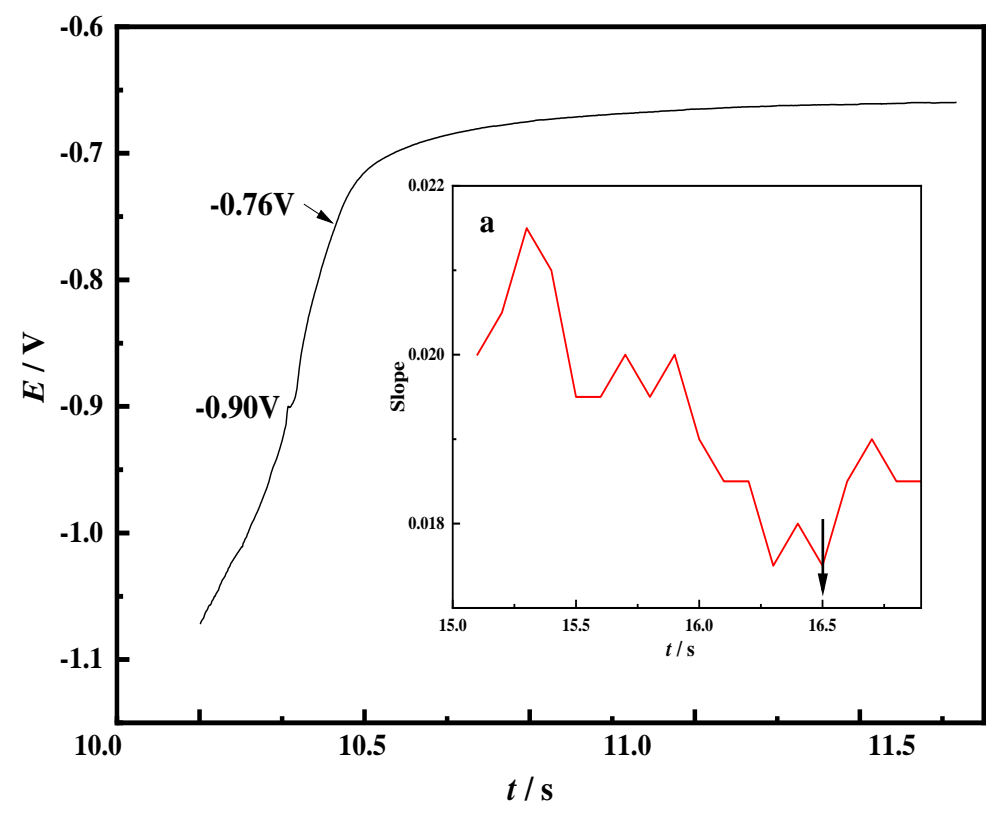

Figure 8. Open circuit chronopotential curve of $\mathrm{Mo}$ electrode in $\mathrm{NaCl}-\mathrm{CaCl}_{2}-\mathrm{LiNiO}_{2}$ molten salt system (a) Slope graph at different times $\left(T=750{ }^{\circ} \mathrm{C}\right.$, reference electrode: Pt electrode).

According to the chronocurrent curve shown in Figure 7, the potential corresponding to the two-step oxidation process of nickel can be roughly judged. In the chronopotential curve shown in Figure 8, the plateau corresponding to $-0.9 \mathrm{~V}$ is more obvious. For differentiation, consider part of the data in the figure. The result is shown in Figure 8a. When $t=16.5$, the slope is the smallest, indicating that the curve has reached the smoothest stage, and the corresponding potential is $-0.76 \mathrm{~V}$. This process is consistent with the appearance mechanism of peak $\mathrm{A}$ in the cyclic voltammetry curve. The plateau near $-0.90 \mathrm{~V}$ exists for a short time, indicating that as the potential increases negatively, the reduction rate increases, and the $\mathrm{Ni}^{2+}$ concentration in the molten salt decreases with the rapid progress of the reaction. This process is consistent with the appearance mechanism of peak $\mathrm{B}$ in the cyclic voltammetry curve. According to the above analysis, in the $\mathrm{NaCl}-\mathrm{CaCl}_{2}-\mathrm{LiNiO}_{2}$ molten salt system, the electrochemical reduction process of $\mathrm{Ni}^{2+}$ on the Mo electrode is $\mathrm{Ni}^{3+} \rightarrow \mathrm{Ni}^{2+} \rightarrow \mathrm{Ni}$

\subsection{The Electrochemical Behavior of $\mathrm{LiNO}_{2}$ in the Solid Electrode on the Mo Cavity Electrode Cyclic Voltammetry}

At a scanning speed of $0.2 \mathrm{~V} / \mathrm{s}$, a cyclic voltammetry test was carried out on the Mo cavity electrode filled with or without $\mathrm{LiNiO}_{2}$ in the $\mathrm{NaCl}-\mathrm{CaCl}_{2}$ molten salt system, and the results are shown in Figure 9. In the $\mathrm{NaCl}-\mathrm{CaCl}_{2}$ molten salt system, there is no oxidation-reduction reaction in the $1.69-0.57 \mathrm{~V}$ potential range, which can be used as the potential scanning range of the Mo cavity electrode filled with $\mathrm{LiNiO}_{2}$. There are three peaks, A, B and C, in the curve, shown by the solid line. From the previous analysis, it is known that peak $\mathrm{C}$ is the alloy peak formed by $\mathrm{Ni}$ and Mo, so there is a two-step electrochemical reduction process for $\mathrm{Ni}^{3+}$ on the Mo electrode. 


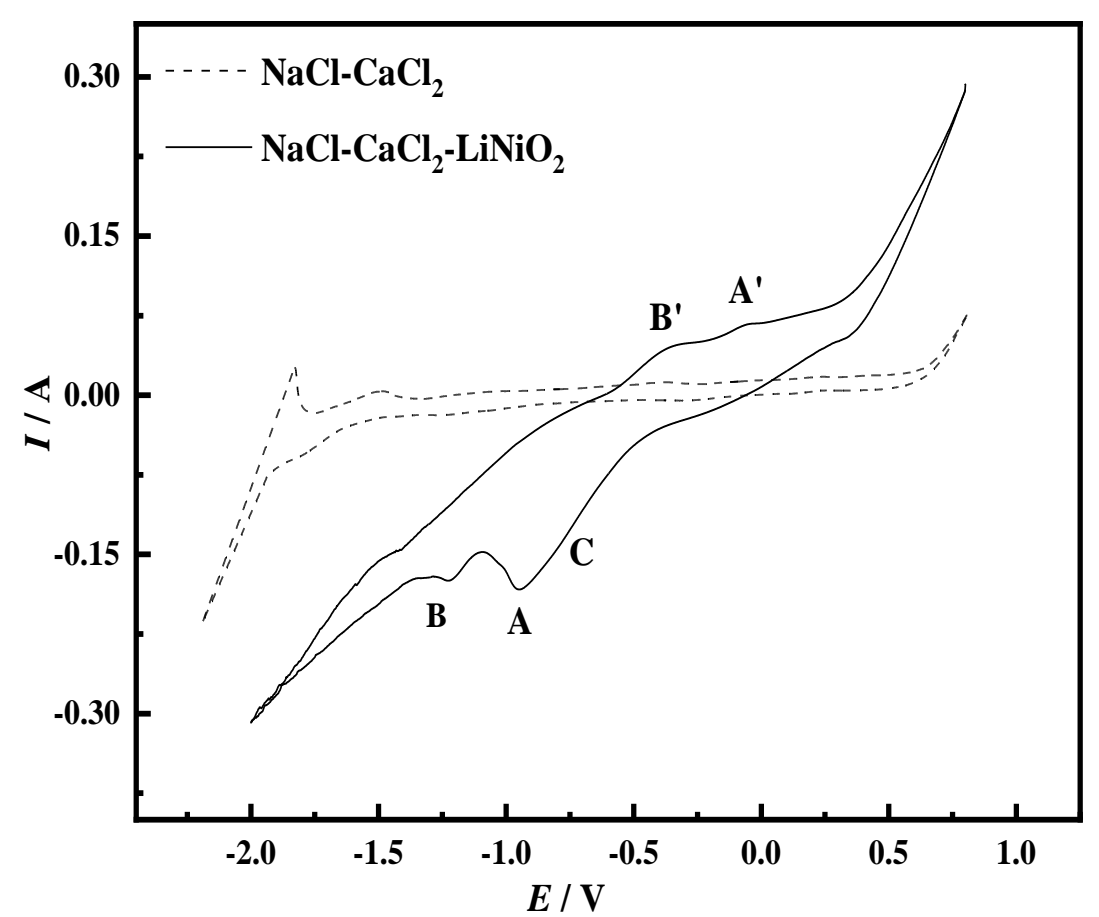

Figure 9. Cyclic voltammetry diagram of Mo cavity electrode filled with or without $\mathrm{LiNiO}_{2}$ in $\mathrm{NaCl}-\mathrm{CaCl}_{2}$ molten salt (scanning speed: $0.2 \mathrm{~V} / \mathrm{s}, \mathrm{T}=750^{\circ} \mathrm{C}$, reference electrode: Pt electrode).

At $750{ }^{\circ} \mathrm{C}$, cyclic voltammetry was performed on the Mo cavity electrode filled with $\mathrm{LiNiO}_{2}$ at different sweep speeds in the $\mathrm{NaCl}-\mathrm{CaCl}_{2}$ molten salt system. The results are shown in Figure 10.

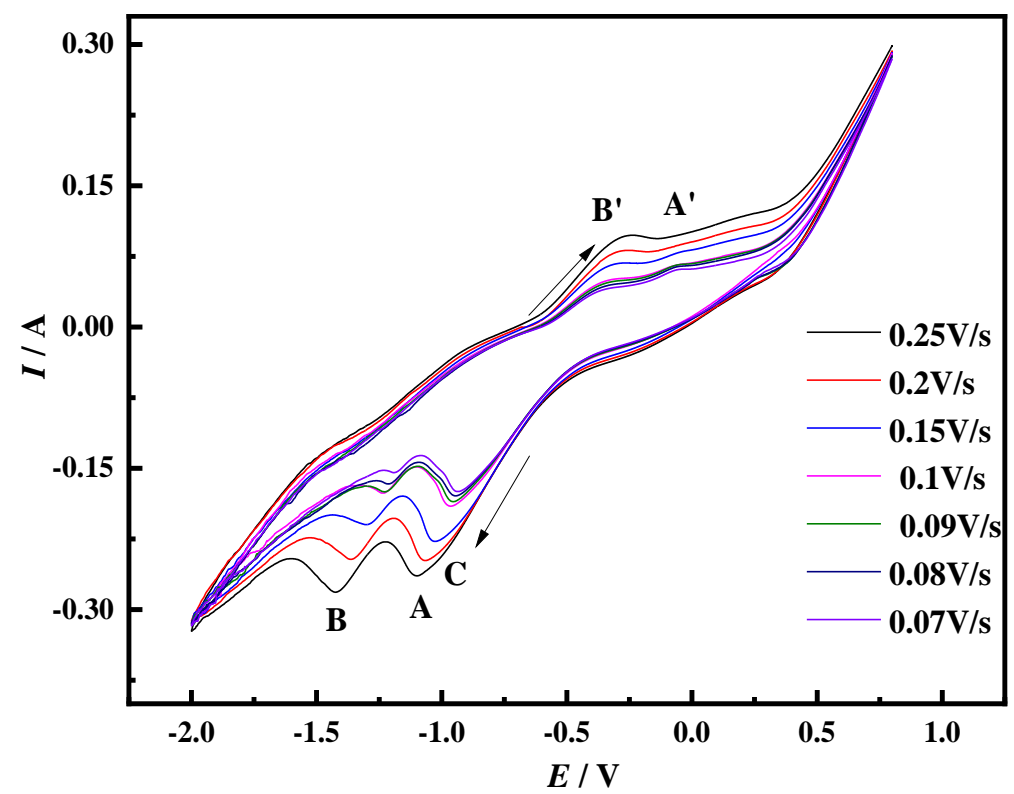

Figure 10. $\mathrm{CV}$ diagram of Mo-hole electrode in $\mathrm{NaCl}-\mathrm{CaCl}_{2}$ molten salt system after filling $\mathrm{LiNiO}_{2}$ (scanning speed: $0.07-0.25 \mathrm{~V} / \mathrm{s}, T=750^{\circ} \mathrm{C}$, reference electrode: Pt electrode).

$\mathrm{LiNiO}_{2}$ belongs to an ionic lattice structure, and the ions on each node in the powder crystal vibrate around their respective equilibrium positions. At $750{ }^{\circ} \mathrm{C}$, as the applied potential increases, the ion vibration that obtains energy increases. When the potential reaches a certain condition, $\mathrm{O}^{2-}$ obtains the activation energy required for displacement, overcomes the binding of surrounding ions, and diffuses to the anode through the molten salt [25]. The exposed $\mathrm{Ni}^{3+}$ maintains the equilibrium of the valence state through an 
electrochemical reduction reaction. When the reduction potential of $\mathrm{Ni}^{3+} \rightarrow \mathrm{Ni}^{2+}$ is reached, the current increases with the increase of the potential, and the process is mainly controlled by the interface charge transfer step. With the negative shift in the scanning potential, $\mathrm{O}^{2-}$ continuously ionizes from $\mathrm{LiNiO}_{2}$ and concentrates near the cathode interface. When the applied potential reaches the peak potential, the concentration of the reactant on the surface of the cathode is maximized to form a concentration polarization phenomenon, which causes the peak potential to shift. The diffusion process cannot be maintained in a stable state so that the electro-chemical reduction rate is not equal to the diffusion rate of $\mathrm{O}^{2-}$, the thickness of the diffusion layer increases and the concentration gradient decreases. Therefore, the diffusion current gradually decreases, and finally peak $\mathrm{A}$ is formed. When the next reduction potential is reached, the formation of the reduction peak B still complies with the above theoretical analysis. When scanning in the forward direction, the Ni elemental substance formed during the reduction process is oxidized again, and each reduction process corresponds to peak $\mathrm{A}^{\prime}$ and peak $\mathrm{B}^{\prime}$ in Figure 10. Under faster scanning speed, the electro-chemical reduction time is shorter, and $\mathrm{O}^{2-}$ ionized from the $\mathrm{LiNiO}_{2}$ matrix accumulates at the cathode interface, forming a thinner transient diffusion layer and a larger concentration gradient. The above phenomenon leads to an increase in current and polarization. Under slower sweep conditions, the long electrochemical reduction time allows $\mathrm{O}^{2-}$ to fully transport at the electrode/molten salt interface to form a thicker transient diffusion layer and a smaller concentration gradient. The above electrochemical behavior leads to the reduction in the oxidation peak and the reduction peak.

In addition, with the increase in the scan rate, the peak potentials of peaks $\mathrm{A}$ and $\mathrm{B}$ continue to move in the negative direction, and there is no obvious oxidation peak corresponding to peak A in the figure. This phenomenon shows that the reduction is gradually turning in an irreversible direction. According to the above analysis, it is judged that peak A corresponds to an irreversible reduction process, and peak B corresponds to a quasi-reversible reduction process.

The curves of $\log v-E_{p c}$ and $\log v-E_{p a}$ of peak $\mathrm{B}$ are plotted respectively according to Figure 10, as shown in Figure 11. The binary primary equations of diffusion coefficient and the number of transferred electrons are listed according to the slope, and the deduced Equations (4) and (5) combined with the primary binary equations are used to calculate the number of transferred electrons at peak B.

$$
\begin{gathered}
E_{\mathrm{pa}}=E^{\circ}(R T / \alpha n F) \ln \left(R T k^{\circ} / \alpha n F\right)+(R T / \alpha n F) \ln v \\
E_{\mathrm{pc}}=E^{\circ}(R T / \alpha n F) \ln \left(R T k^{\circ} /(1-\alpha) n F\right)+(R T /(1-\alpha) n F) \ln v
\end{gathered}
$$
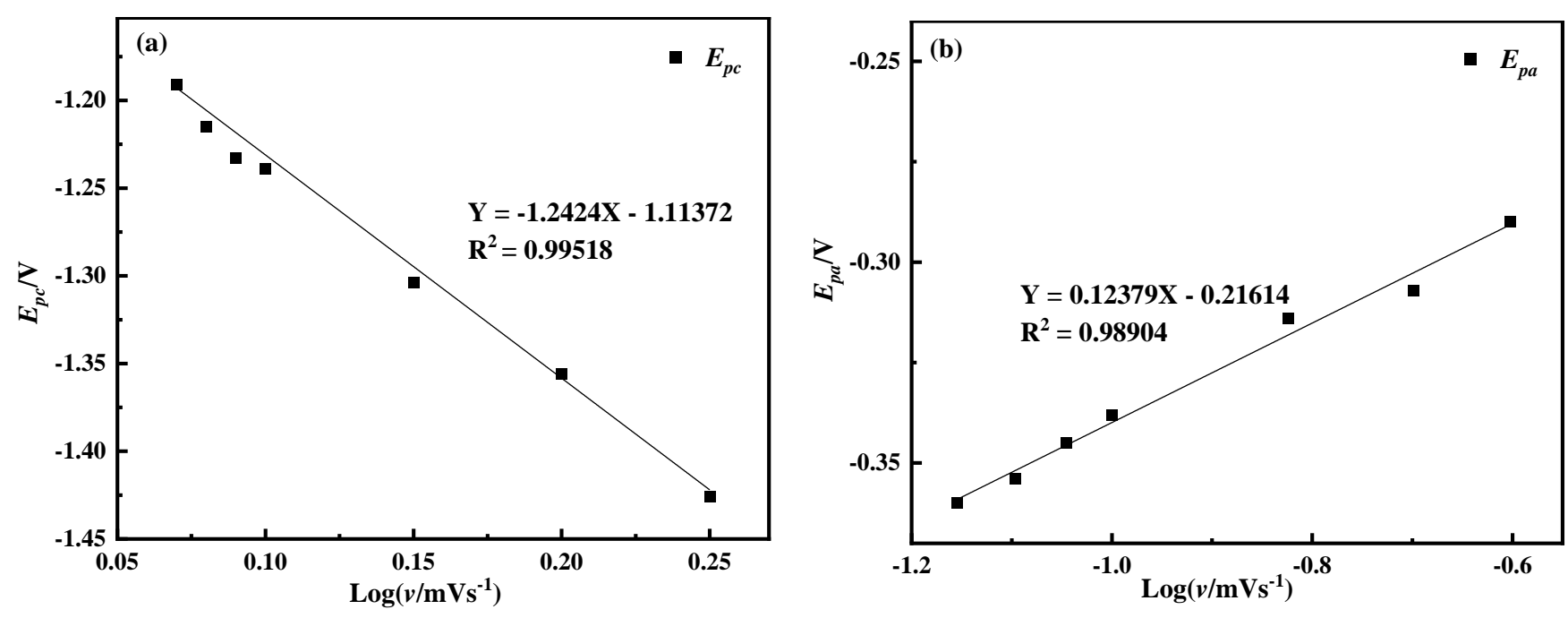

Figure 11. The $\log v-E_{p c}$ and $\log v-E_{p a}$ curves of peak $\mathrm{B}\left(\mathrm{A}=0.32 \mathrm{~cm}^{2}\right)(\mathbf{a}) \log v-E_{p c}(\mathbf{b}) \log v-E_{p a}$. 
According to Figure 11, the linear equation of $E_{p c}$ and $\log v$ can be obtained as Equation (6), and the linear equation of $E_{p a}$ and $\log v$ is Equation (7).

$$
\begin{aligned}
& y=-1.2424 x-1.11372 \\
& y=0.12379 x-0.21614
\end{aligned}
$$

In the formula: $R$-molar gas constant $(8.3145 \mathrm{~J} / \mathrm{mol} / \mathrm{K}), \mathrm{T}$-temperature $(\mathrm{K}), n$ - electron transfer number, $F$-Faraday's constant $(96,485 \mathrm{C} / \mathrm{mol})$.

The solution shows that $n=1.8$, which is approximately equal to 2 . Therefore, the number of electrons transferred in the electrochemical reduction reaction corresponding to peak $\mathrm{B}$ should be 2 . In summary, $\mathrm{Ni}^{3+}$ reduction is divided into two steps, namely $\mathrm{Ni}^{3+}$ $+\mathrm{e}^{-}=\mathrm{Ni}^{2+}, \mathrm{Ni}^{2+}+2 \mathrm{e}^{-}=\mathrm{Ni}$. The $i_{p c}-E_{p c}-v^{1 / 2}$ curves of peaks A and B were respectively drawn according to Figure 10, as shown in Figure 12. It can be seen from the figure that the $i_{p c}$ and $v^{1 / 2}$ of the two have a linear relationship. It can be judged that the reduction in $\mathrm{Ni}^{3+}$ to $\mathrm{Ni}^{2+}$ is controlled by the electron transfer step, and the reduction in $\mathrm{Ni}^{2+}$ to $\mathrm{Ni}$ is controlled by the electron transfer step and the diffusion process.
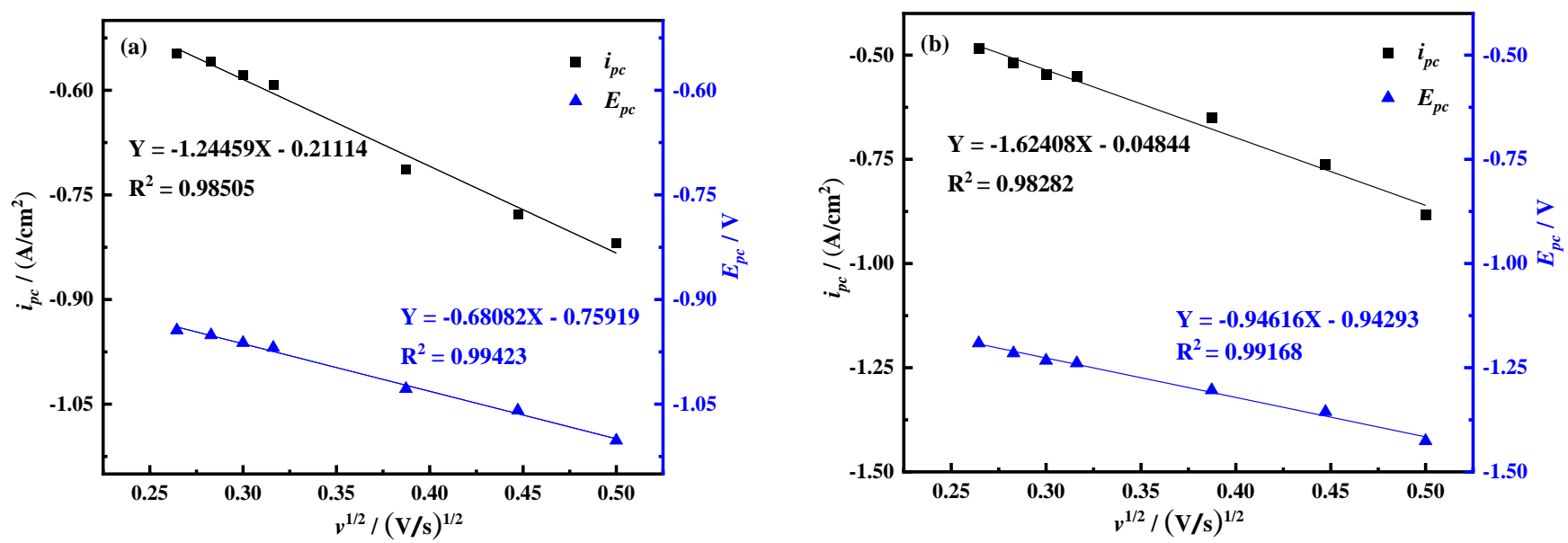

Figure 12. The $i_{p c}-v^{1 / 2}$ and $E_{p c}-v^{1 / 2}$ curves of reduction peaks A and B (a) peaks A (b) peaks B.

\subsection{Preparation of Nickel by Electrolysis of $\mathrm{LiNiO}_{2}$ with Molten Salt Constant Current}

Constant current electrolysis is used to study the reduction process of $\mathrm{Ni}$, and its intermediate products, combined with the reaction process, the interface diffusion and transfer of Ni3+ reduction, are analyzed, and the reduction mechanism of Ni electrolysis is explored. The electrolysis mechanism diagram is shown in Figure 13. I have confirmed.

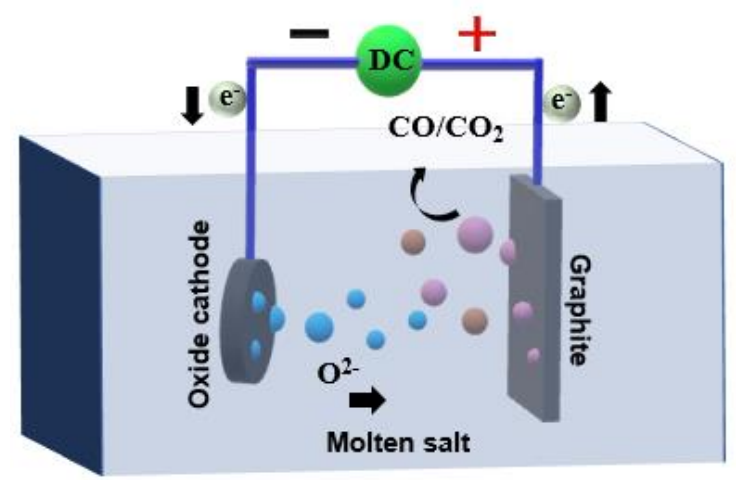

Figure 13. Electrolysis mechanism diagram. 
Under the condition of $750{ }^{\circ} \mathrm{C}$ and $10 \mathrm{~h}$ of electric deoxidation time, this study selects different currents to recover and prepare metallic nickel. The products of $10 \mathrm{~h}$ deoxygenation at different currents are shown in Figure 14a. Under the conditions of $0.01 \mathrm{~A}$ and $10 \mathrm{~h}$, $\mathrm{Ni}$ and $\mathrm{NiO}$ were mainly formed on the surface of the product. Although $\mathrm{Ni}$ and $\mathrm{NiO}$ also existed inside the product, there was more $\mathrm{NiO}$ than the surface. The above phenomenon shows that under this current condition, the electrochemical reaction continuously extends from the outside to the inside along the three-phase interface (3 PIs), and this behavior causes part of the $\mathrm{NiO}$ inside the product to fail to continue to be reduced.
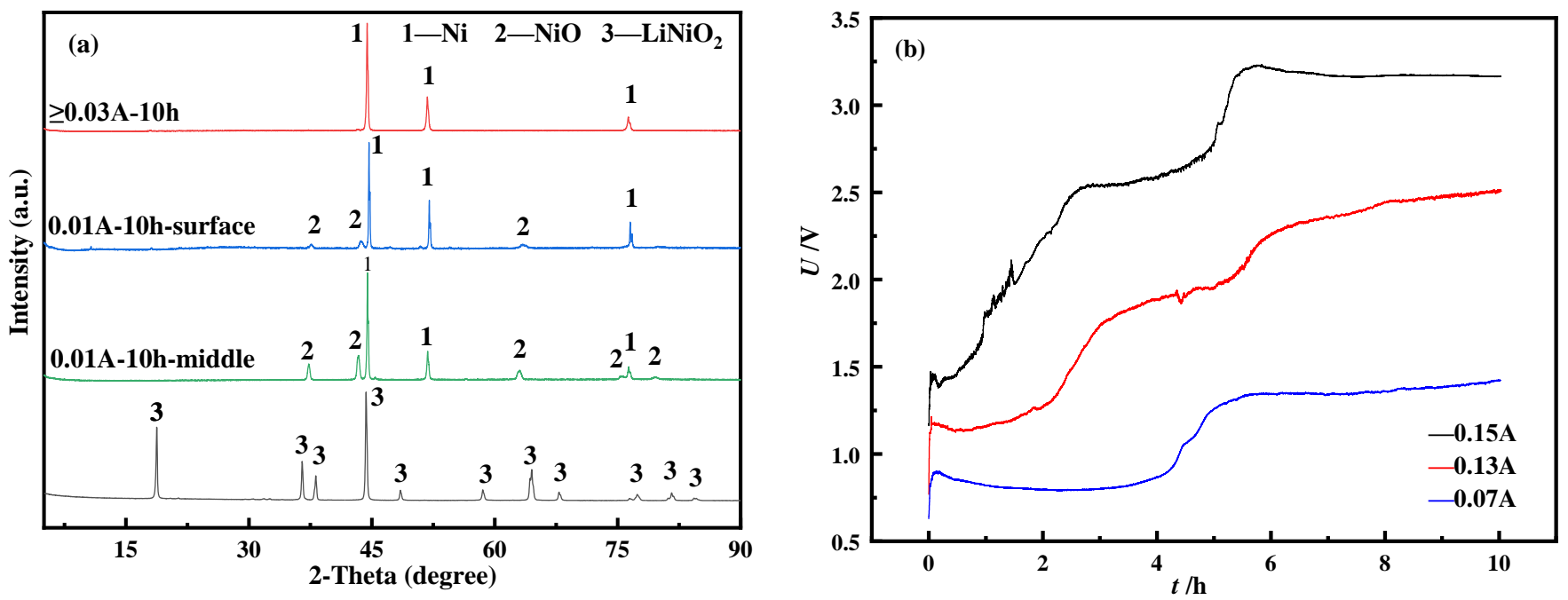

Figure 14. (a) XRD patterns of the product after $10 \mathrm{~h}$ electrolysis under different current conditions (b) $U$ - $t$ diagram of electrolysis at $750{ }^{\circ} \mathrm{C}$ for $10 \mathrm{~h}$ at $0.07-0.15 \mathrm{~A}$.

In addition, the presence of $\mathrm{NiO}$ also proves again that there is a two-step electrochemical reduction behavior of $\mathrm{Ni}^{3+}$ in $\mathrm{LiNiO}_{2}$. When the current is greater than or equal to $0.03 \mathrm{~A}$, the products after $10 \mathrm{~h}$ are all Ni elemental. It can be seen that under the same deoxygenation time condition, a larger current can promote the reduction reaction, so that $\mathrm{NiO}$ can continue to be reduced to a Ni elementary substance. It can be seen that under the same deoxygenation time condition, a larger current can promote the reduction reaction, so that $\mathrm{NiO}$ can continue to be reduced to a Ni elementary substance. It can be seen from Figure $14 \mathrm{~b}$ that different currents cause differences in the degree of electron accumulation at the electrodes, resulting in different starting positions of the curve. In addition, comparing the time range corresponding to each reaction platform on the three curves in the figure, the first platform in the $U$ - $t$ curve measured under the condition of $0.07 \mathrm{~A}$ current corresponds to about $4 \mathrm{~h}$, while the second platform corresponds to the duration of "shorter". The above phenomenon shows that in the first electrochemical reduction process, more $\mathrm{NiO}$ and a small amount of $\mathrm{Ni}$ element are mainly formed. Therefore, in the second reduction process, the Ni elementary substance is formed faster. The current condition of $0.15 \mathrm{~A}$ promotes the progress of electrochemical reduction, so that the reduction reaction is concentrated in the second step of the reaction process. Under the condition of $0.13 \mathrm{~A}$, the whole reaction process is relatively stable, and there is a good transition time. Under the conditions of an electrolysis time of $10 \mathrm{~h}$ and currents of $0.07 \mathrm{~A}, 0.13 \mathrm{~A}$ and $0.15 \mathrm{~A}$, this study calculates the actual charge and the theoretical charge according to Equations (8) and (9), and finally calculates the current efficiency of the three, as shown in the Table 1 shown.

$$
\begin{gathered}
Q=I t \\
Q=n z F
\end{gathered}
$$


Table 1. $10 \mathrm{~h}$ electrolysis efficiency at $750{ }^{\circ} \mathrm{C}$ at $0.07-0.15 \mathrm{~A}$.

\begin{tabular}{ccc}
\hline Electrolysis Conditions & LiNiO $_{2} / \mathbf{g}$ & Current Efficiency/\% \\
\hline $0.07 \mathrm{~A}, 10 \mathrm{~h}$ & 0.665 & 77.9 \\
$0.13 \mathrm{~A}, 10 \mathrm{~h}$ & 0.670 & 42.2 \\
$0.15 \mathrm{~A}, 10 \mathrm{~h}$ & 0.668 & 36.5 \\
\hline
\end{tabular}

In the formula, $n$ is the amount of substance in the product under theoretical conditions, $z$ is the number of transferred electrons, $t$ is time (s), and $F$ is Faraday's constant $(96,485 \mathrm{C} / \mathrm{mol})$.

It can be seen from the table that as the current increases, the current efficiency decreases. This situation is because the increase in current causes the actual charge to increase, while the theoretical charge has a relatively small change, which eventually leads to a gradual decrease in current efficiency. At $0.13 \mathrm{~A}$ and $750{ }^{\circ} \mathrm{C}, 0.7 \mathrm{~g}$ lithium nickelate was subjected to constant current deoxygenation studies for $0.5 \mathrm{~h}, 4 \mathrm{~h}$ and $6 \mathrm{~h}$, respectively. Further study on the influence of time on the electrochemical reduction process through product analysis is needed. The result is shown in Figure 15.
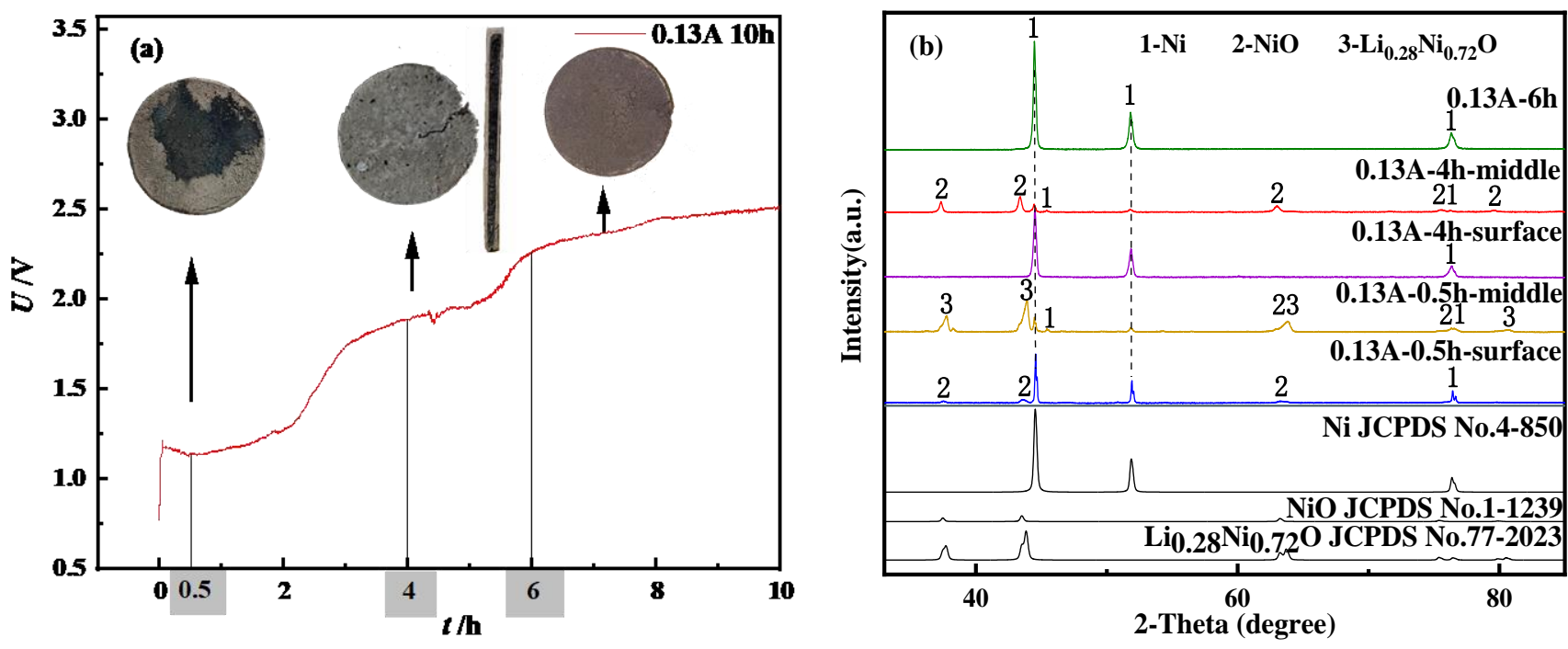

Figure 15. (a) $0.13 \mathrm{~A} U$ - $t$ curve of $10 \mathrm{~h}$ electrolysis (b) $0.13 \mathrm{~A}$ XRD detection of deoxidation products at different times.

The $U-t$ curve is shown in Figure 15a. In the reduction process of $\mathrm{Ni}^{3+}$, different reduction stages correspond to different potential platforms. According to the XRD pattern of the $0.5 \mathrm{~h}$ product shown in Figure 15b, it can be seen that the inside of the particles is mainly $\mathrm{Ni}$ and $\mathrm{NiO}$, and most of the intermediate products $\mathrm{Li}_{0.28} \mathrm{Ni}_{0.72} \mathrm{O}$, which is only caused by the slow extension of the three-phase interface during the reduction process. At this time, the black product inside the product is $\mathrm{NiO}$ and $\mathrm{Li}_{0.28} \mathrm{Ni}_{0.72} \mathrm{O}$, and the steel gray product appears at the three-phase interface, which is metallic Ni. As the reaction progresses, $\mathrm{O}^{2-}$ continuously ionizes from the $\mathrm{LiNiO}_{2}$ matrix and concentrates near the cathode. At the same time, the produced $\mathrm{Ni}$ element adheres to the surface of the substrate as a conductor and further hinders the ionization of $\mathrm{O}^{2-}$ and the transfer of electrons. The above phenomena cause electrons to accumulate in the electric double layer, and eventually lead to a negative increase in potential. When the second step reduction potential is reached, a second platform corresponding to $4 \mathrm{~h}$ is formed in the figure. Combined with the XRD test results, it can be seen that the surface of the $4 \mathrm{~h}$ product is mainly $\mathrm{Ni}$, and the internal components are mainly $\mathrm{Ni}$ and $\mathrm{NiO}$. The black substance inside the product gradually decreases, indicating that, as time goes by, $\mathrm{O}^{2-}$ in $\mathrm{Li}_{0.28} \mathrm{Ni}_{0.72} \mathrm{O}$ is continuously removed and, finally, $\mathrm{NiO}$ is formed. This phenomenon also further confirms that $\mathrm{Ni}^{3+}$ conducts electricity from the outside to the inside of the electrode surface along the three-phase 
interface. When the time was increased to $6 \mathrm{~h}$, the $\mathrm{NiO}$ inside the product was completely deoxidized, and $\mathrm{Ni}^{2+}$ was reduced to elemental $\mathrm{Ni}$. As time continues to extend, there are no other oxidation-reduction reactions in the molten salt, and the potential ultimately remains in a relatively stable state. The atomic structure diagram is shown in Figure 16.
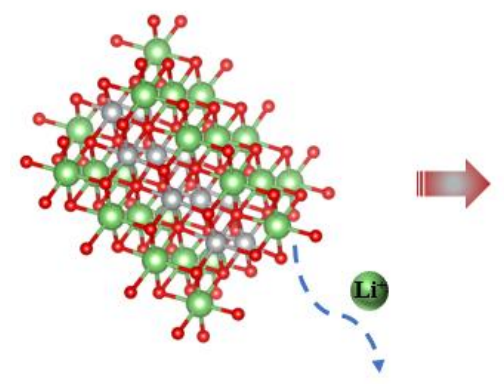
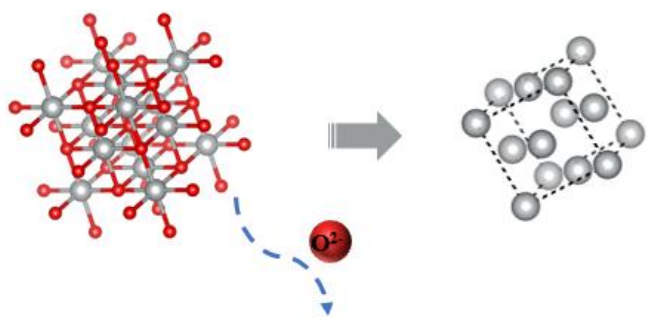

$\mathrm{O}^{2-} \mathrm{Ni}$

Figure 16. $\mathrm{LiNiO}_{2}$ atomic structure change during electrolysis.

Figure 17 is the SEM, EDS and surface scan detection spectrum of the 10 h electrolysis product under different multiple conditions. It can be seen that the metallic nickel has a honeycomb skeleton structure, and its content reaches $96.39 \%$. The electrolytic metallic nickel is silver-white with metallic luster and magnetic.

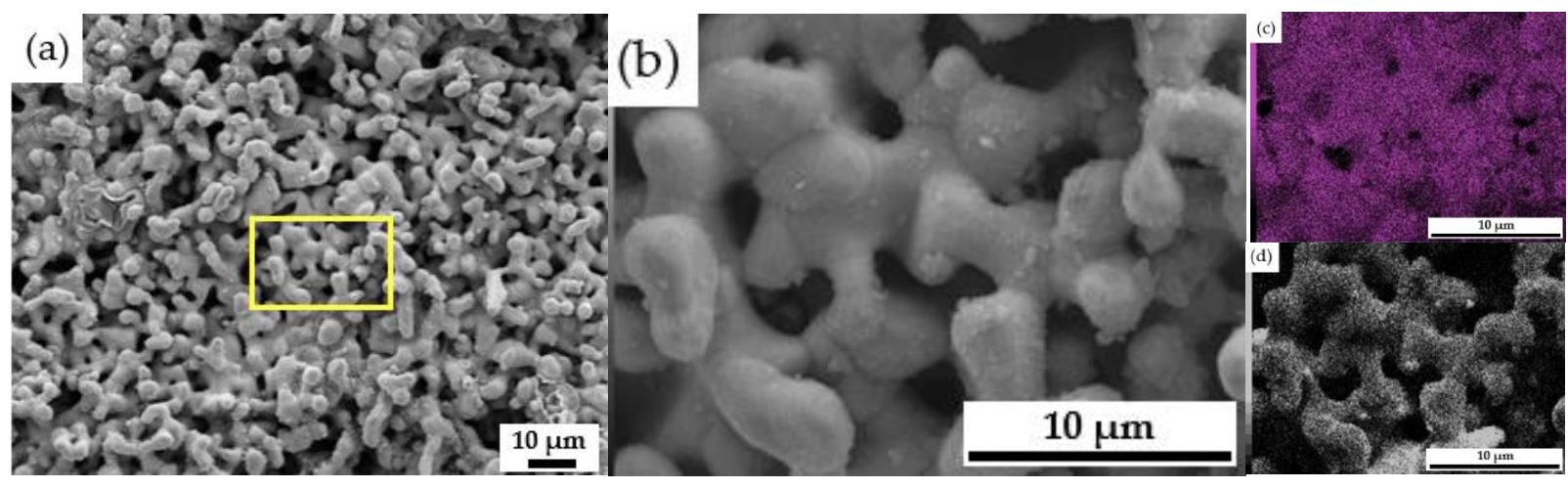

Figure 17. SEM images of electrolyzed products at 1000 times (a) and 5000 times (b) after $10 \mathrm{~h}$, as well as EDS and surface scan maps at 5000 times ((c): Ni element (d): O element).

XPS detection was performed on the electrolysis products after $4 \mathrm{~h}$ and $10 \mathrm{~h}$, and the results are shown in Figures 18 and 19, respectively. It can be seen from the XPS spectrum that elemental nickel appears in the product of electrolysis at $4 \mathrm{~h}$. As the electrolysis time increases, more $\mathrm{Ni}^{2+}$ is reduced to elemental $\mathrm{Ni}$, and the peaks corresponding to elemental $\mathrm{Ni}$ in the XPS spectrum increase. Compared with the XPS spectrum after $4 \mathrm{~h}$ of electrolysis, the $2 p$ peak of $\mathrm{Ni}$ after $10 \mathrm{~h}$ of electrolysis is weaker and wider, while the $2 \mathrm{p}$ peak of part of $\mathrm{Ni}^{2+}$ is strengthened. This phenomenon is caused by the increase in oxides on the surface of the sample [26]. 

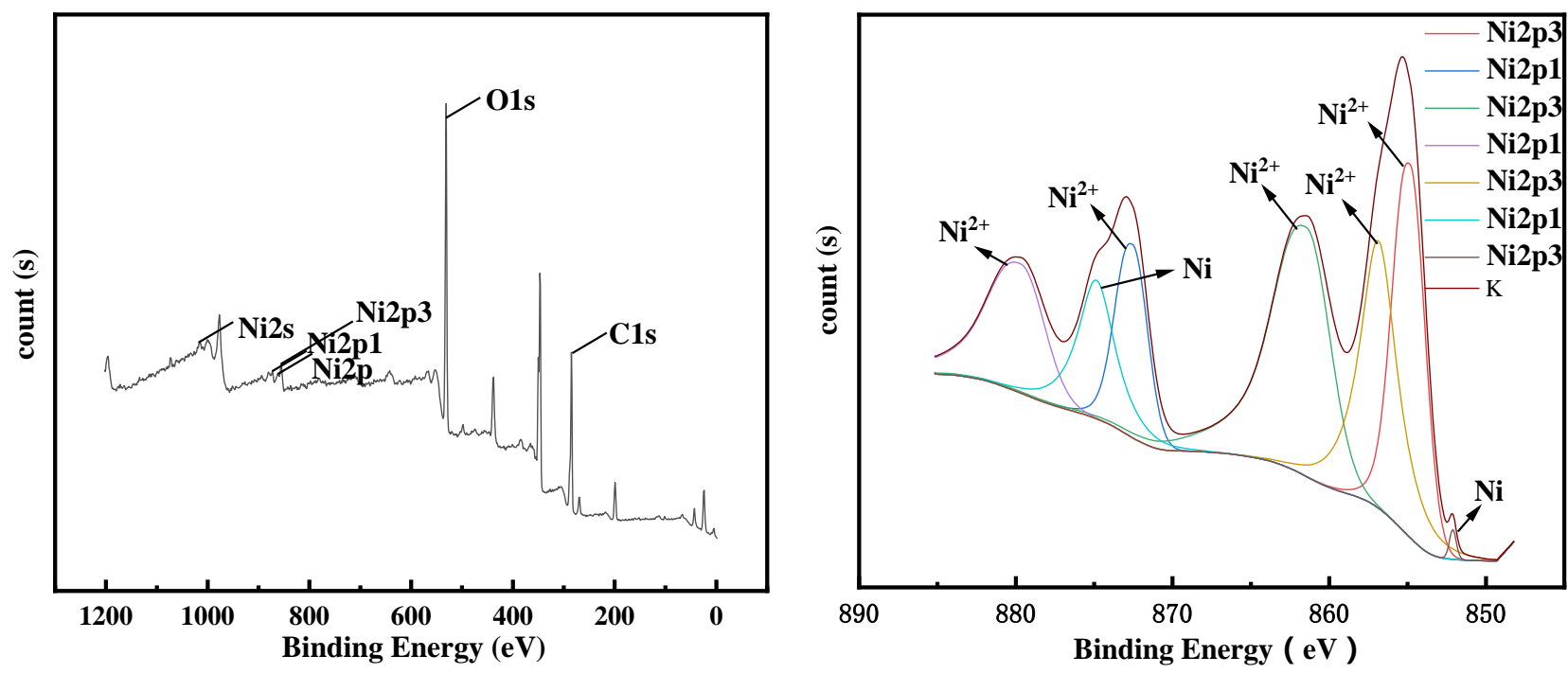

Figure 18. XPS test results of the product after $0.13 \mathrm{~A}$ electrolysis for $4 \mathrm{~h}$.
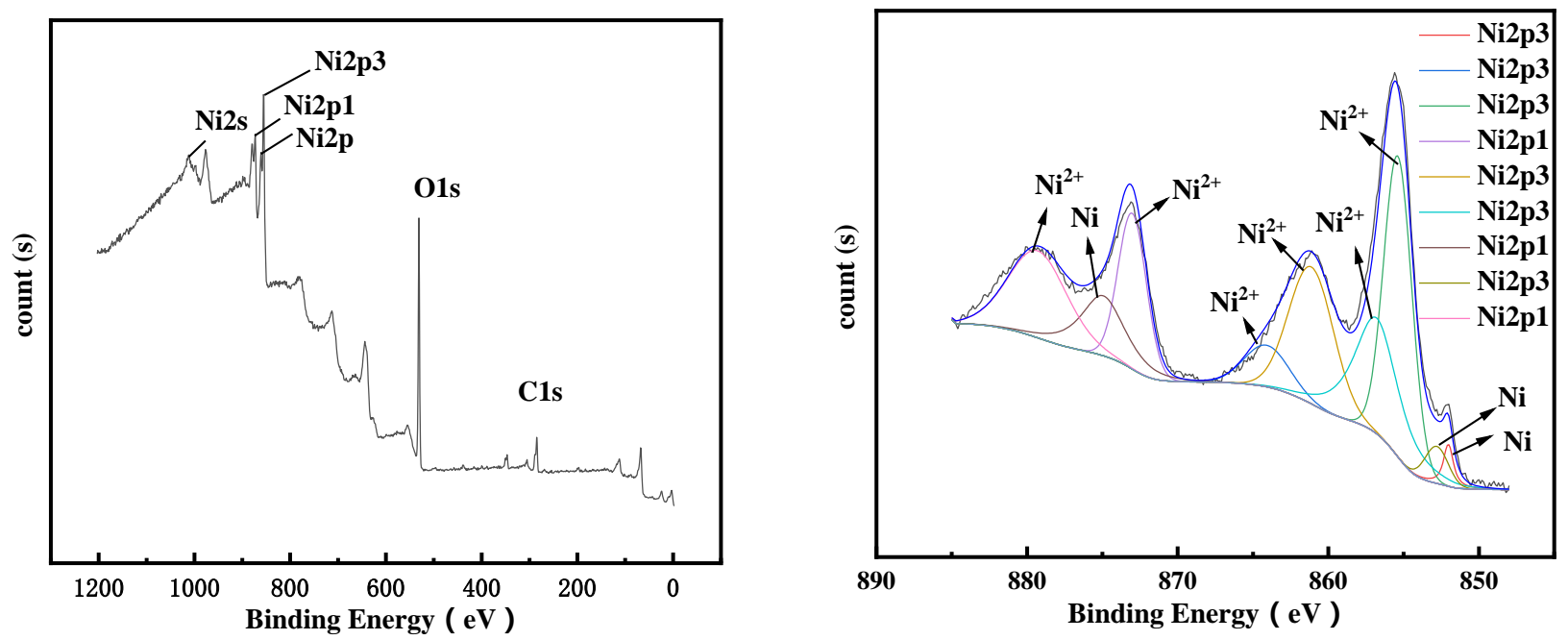

Figure 19. XPS test results of the product after 0.13 A electrolysis for $10 \mathrm{~h}$.

\subsection{The Behavior of Lithium under Constant Current Conditions}

$\mathrm{LiNiO}_{2}$ belongs to the trigonal crystal system. The oxygen atoms at position $6 \mathrm{c}$ are closely packed in cubic form to form a crystal framework, which occupy positions 3a and $3 \mathrm{~b}$, respectively. $\mathrm{Li}$ atoms and $\mathrm{Ni}$ atoms are located in alternate octahedral positions in the framework, with obvious layered structure, and the space group is $\mathrm{R} / 3 \mathrm{~m}$. Due to the special electronic arrangement of $\mathrm{Ni}^{2+}$, part of $\mathrm{Ni}^{2+}$ existing in $\mathrm{LiNiO}_{2}$ will occupy the position of $\mathrm{Ni}^{3+}$. In order to maintain charge balance and the similar atomic radii of $\mathrm{Ni}^{2+}$ and $\mathrm{Li}^{+}$, the position of $\mathrm{Li}^{+}$will also be occupied by $\mathrm{Ni}^{2+}$, and at the same time, during the electrolysis process, $\mathrm{Ni}^{2+}$ will transform to $\mathrm{Ni}^{3+}$ with a smaller radius, causing the structure to change, and the position of $\mathrm{Li}^{+}$will further lose the ability to insert lithium $[27,28]$. In addition, under the layered structure, van der Waals force and ionic bonds are used to maintain the interlayer and the inner layer, respectively. Because the van der Waals force is weak, the $\mathrm{Li}^{+}$in the layer is required to maintain the stability of the structure through electrostatic action. However, there is a big difference between the $\mathrm{Li}^{+}\left(1 \mathrm{~s}^{2}\right)$ energy level and the $\mathrm{O}^{2-}$ energy level, while the $\mathrm{Ni}^{3+}\left(3 \mathrm{~d}^{7}\right)$ and $\mathrm{O}^{2-}\left(2 \mathrm{p}^{6}\right)$ energy levels are relatively similar, which makes the electron cloud overlap between $\mathrm{Li}-\mathrm{O}$ more than that between $\mathrm{Ni}-\mathrm{O}$. If it was smaller, the Li-O bond energy would eventually be weaker. Therefore, the 
$\mathrm{Li}-\mathrm{O}$ bond will be preferentially broken during the electrolysis process, and $\mathrm{Li}^{+}$will escape from the Ni-O layer [29].

In order to further study the electrochemical behavior of $\mathrm{Li}^{+}$in molten salt or $\mathrm{Li}^{+}$in cathode reduction particles, thermodynamic calculations of related reactions are carried out. Equation (10) shows that the Gibbs free energy of the reaction is negative. Therefore, the reduction in $\mathrm{Li}^{+}$will proceed with more difficulty. During the electrochemical scanning process, the redox peak of Li did not appear, which is consistent with the analysis of the cyclic voltammogram.

$$
4 \mathrm{Li}+\mathrm{O}_{2}=2 \mathrm{Li}_{2} \mathrm{O} \quad \Delta G^{\Theta}=-923.712 \mathrm{~kJ} / \mathrm{mol}
$$

In this study, $0.7 \mathrm{~g}$ of $\mathrm{LiNiO}_{2}$ powder was made into the cathode and smooth graphite flakes were used as the anode, and they were put into $\mathrm{NaCl}-\mathrm{CaCl}_{2}$ molten salt and electrolyzed at $750{ }^{\circ} \mathrm{C}$ with a constant current of $0.18 \mathrm{~A}$ for $10 \mathrm{~h}$. After the electrolysis, XRD analysis was performed on the molten salt and the product near the cathode, and the result is shown in Figure 20. It can be seen from Figure 20 that the product is elemental Ni after electrolysis for $10 \mathrm{~h}$ under the condition of $0.18 \mathrm{~A}$ current. After electrolysis, there is $\mathrm{LiCl}$ in the XRD of the molten salt near the cathode. The above phenomenon shows that $\mathrm{Li}^{+}$in $\mathrm{LiNiO}_{2}$ finally enters the molten salt. The constant cell voltage electrolysis in the two-electrode system further supports the conclusions obtained by cyclic voltammetry, square wave voltammetry, open circuit potential and chronoamperometry.

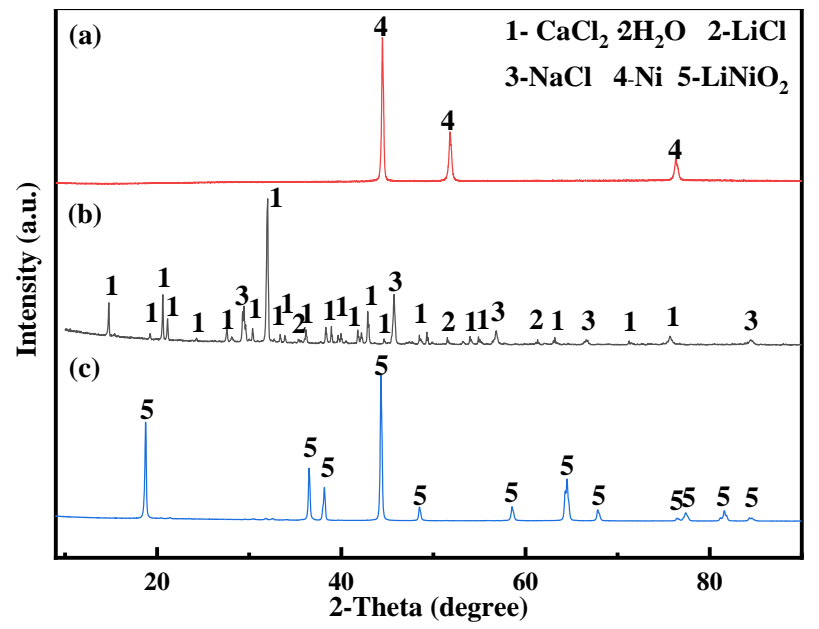

Figure 20. (a) XRD pattern of the product after $10 \mathrm{~h}$ of $0.18 \mathrm{~A}$ constant current electrolysis (b) XRD pattern of molten salt near cathode after electrolysis $\left(T=750{ }^{\circ} \mathrm{C}\right)(\mathbf{c}) \mathrm{XRD}$ analysis of $\mathrm{LiNiO}_{2}$ in molten salt.

\section{Conclusions}

The electrochemical reduction behavior of $\mathrm{LiNiO}_{2}$ in $\mathrm{NaCl}-\mathrm{CaCl}_{2}$ molten salt (molar ratio: 1:1) and on the Mo cavity electrode was investigated by cyclic voltammetry, square wave voltammetry, chronoamperometry and open-circuit potential at $750{ }^{\circ} \mathrm{C}$. Through the method of constant current electrolysis, the process of preparing metal nickel by reduction of lithium nickelate was analyzed, and the following conclusions drawn:

(1) The electrochemical reduction process of $\mathrm{Ni}^{3+}$ in the two research systems is an irreversible-quasi-reversible reaction process, and the electro-chemical reduction process is divided into two steps. There are alloy peaks formed by Ni and Mo in the cyclic voltammetry curves of the two systems.

(2) Under $10 \mathrm{~h}, 0.01-0.15 \mathrm{~A}$ current conditions, the material reduction process is $\mathrm{LiNiO}_{2}$ $\rightarrow \mathrm{NiO} \rightarrow \mathrm{Ni}$. When the current is $0.01 \mathrm{~A}$, the product is elemental $\mathrm{Ni}$ and a small amount of $\mathrm{NiO}$. When the current is not less than $0.03 \mathrm{~A}$, the product is mainly metallic 
$\mathrm{Ni}$. In the whole process, under the conditions of $0.07 \mathrm{~A}$ and $10 \mathrm{~h}$ of electrolysis, the highest current efficiency is $77.9 \%$.

(3) At $0.13 \mathrm{~A}$ and $0.5 \mathrm{~h}$ after electrolysis, the intermediate product $\mathrm{Li}_{0.28} \mathrm{Ni}_{0.72} \mathrm{O}$, produced in a short time, is chemically dissolved in the molten salt, and finally deoxidized to produce $\mathrm{NiO}$. After the electrolysis time was extended to $6 \mathrm{~h}$, the product was metallic $\mathrm{Ni}$. The presence of $\mathrm{LiCl}$ in the molten salt near the cathode after electrolysis indicates that $\mathrm{Li}^{+}$has not been reduced during the entire reaction, but entered the molten salt in the form of ions.

Author Contributions: Conceptualization, H.L., J.L., C.L.; methodology, H.Y., Y.F., Z.C.; validation, C.L., H.Y., J.W.; investigation, H.L., J.L., J.W.; resources, Z.C., Y.F. All authors have read and agreed to the published version of the manuscript.

Funding: This research was funded by the National Natural Science Foundation of China (No. 51774143).

Institutional Review Board Statement: Not applicable.

Informed Consent Statement: Not applicable.

Data Availability Statement: Data sharing is not applicable to this article.

Conflicts of Interest: The authors declare no conflict of interest.

\section{References}

1. Li, Z.Q.; Zhuang, X.N.; Song, X.L.; Li, F.; Li, Y.S.; Gu, W.H.; Bai, J.F. Research progress on recovery of the cathode material from spent lithium-ion batteries by pyrometallurgy. Environ. Eng. 2021, 39, 115-122, 146. [CrossRef]

2. Hao, T.; Zhang, Y.J.; Dong, P.; Liang, F.; Duan, J.G.; Meng, Q.; Xu, B. Review on recycling cathode materials of spent ternary power lithium-ion batteries. Bull. Chin. Ceram. Soc. 2018, 37, 2451-2456. [CrossRef]

3. Linda, G. The future of automotive lithium-ion battery recycling: Charting a sustainable course. Sustain. Mater. Technol. 2014, 1-2, 2-7. [CrossRef]

4. Chen, X.P.; Ma, H.R.; Luo, C.B.; Zhou, T. Recovery of valuable metals from waste cathode materials of spent lithium-ion batteries using mild phosphoric acid. J. Hazard. Mater. 2017, 326, 77-86. [CrossRef]

5. Cou, H.P.; Pei, Z.Y.; Zhou, G.Z.; Liu, C.; Lv, D.; Chen, X.G.; Yu, Y.; Li, M.C. Study on recycle of the spent ternary Li-ion battery by pyrometallurgical process. China Nonferr. Metal. 2019, 8, 79-83. [CrossRef]

6. Guo, M.M.; Xi, X.L.; Zhang, Y.H.; Yu, S.W.; Long, X.L.; Jiang, Z.K.; Nie, Z.R.; Xu, K.H. Recovering valuable metals from waste ternary cathode materials of power battery by combined high temperature hydrogen reduction and hydrometallurgy. Chin. J. Nonferr. Met. 2020, 30, 1415-1426.

7. Hu, J.T.; Zhang, J.L.; Li, H.X.; Chen, Y.Q.; Wang, C.G. A promising approach for the recovery of high value-added metals from spent lithium-ion batteries. J. Power Sources 2017, 351, 192-199. [CrossRef]

8. Lupi, C.; Pasquali, M. Electrolytic nickel recovery from lithium-ion batteries. Miner. Eng. 2003, 16, 537-542. [CrossRef]

9. Sun, M.C.; Ye, H.; Chen, W.J.; Li, H.Y.; Xiao, J. Study on Recovering Valuable Metals from Spent Lithium-ion Batteries. Nonferr. Metal. Extr. Metal. 2019, 3, 68-72.

10. Li, X.Y. Research on Key Technologies of Partial Porous Externally Pressurized Gas Bearing; Harbin Institute of Technology: Harbin, China, 2019.

11. Wang, X.F.; Kong, X.H.; Zhao, Z.Y. Recovery of noble metal in lithium ion battery. Battery. Bimon. 2001, 1, 14-15. [CrossRef]

12. Li, L.; Fan, E.; Guan, Y.; Zhang, X.; Chen, R. Sustainable recovery of cathode materials from spent lithium-ion batteries using lactic acid leaching system. ACS Sustain. Chem. Eng. 2017, 5, 5224-5233. [CrossRef]

13. Zhang, H.J.; Cheng, J.H.; Zhu, C.; Yang, J.; Gu, M. Recovery of Copper, Cobalt and Nickel from Spent Lithium Ion Batteries by a Combined Process of Acid Leaching and Bioleaching. Hydrometall. China 2019, 38, 22-27. [CrossRef]

14. Chen, G.Z.; Fray, D.J.; Farthing, T.W. Direct electrochemical reduction of titanium dioxide to titanium in molten calcium chloride. Cheminform 2010, 32, 361-364. [CrossRef]

15. Zhu, Y.; Meng, M.A.; Wang, D. Electrolytic reduction of mixed solid oxides in molten salts for energy efficient production of the TiNi alloy. Chin. Sci. Bull. 2006, 51, 2535-2540. [CrossRef]

16. Qiu, G.; Wang, D.; Meng, M.; Jin, X.; Chen, G.Z. Electrolytic synthesis of $\mathrm{TbFe}_{2}$ from $\mathrm{Tb}_{4} \mathrm{O}_{7}$ and $\mathrm{Fe}_{2} \mathrm{O}_{3} \mathrm{Powders}$ in molten $\mathrm{CaCl}_{2}$. J. Electroanal. Chem. 2006, 589, 139-147. [CrossRef]

17. Peng, J.; Chen, H.; Jin, X.; Wang, T.; Wang, D.; Chen, G.Z. Phase-Tunable Fabrication of Consolidated ( $\alpha+\beta)$-TiZr Alloys for Biomedical Applications through Molten Salt Electrolysis of Solid Oxides. Chem. Mater. 2009, 21, 5187-5195. [CrossRef]

18. Chen, G.Z.; Gordo, E.; Fray, D.J. Direct electrolytic preparation of chromium powder. Metall. Mater. Trans. B 2004, 35, $223-233$. [CrossRef] 
19. Gordo, E.; Chen, G.Z.; Fray, D.J. Toward optimisation of electrolytic reduction of solid chromium oxide to chromium powder in molten chloride salts. Electrochim. Acta 2004, 49, 2195-2208. [CrossRef]

20. Zhang, B.; Xie, H.; Lu, B.; Chen, X.; Xing, P.; Qu, J.; Song, Q.; Yin, H. A Green Electrochemical Process to Recover Co and Li from Spent $\mathrm{LiCoO}_{2}$-Based Batteries in Molten Salts. ACS Sustain. Chem. Eng. 2019, 7, 13391-13399. [CrossRef]

21. Chen, G.Z.; Fray, D.J. Understanding the electro-reduction of metal oxides in molten salts. In Proceedings of the Symposium of Recent Advances in Non-Ferrous Metals Processing, 2004 TMS Annual Meeting, Charlotte, NC, USA, 14-18 March 2004.

22. Li, N.; Peng, Y.; Chen, Z.; Xiong, W.; Li, S. Preparation of Mg-Zr Alloys through Direct Electro-deoxidation of $\mathrm{MgO}_{\mathrm{Z}} \mathrm{ZrO}{ }_{2}$ in $\mathrm{CaCl}_{2}-\mathrm{NaCl}$ Molten Salt. Electrochim. Acta 2021, 372, 137816. [CrossRef]

23. Konishi, H.; Nohira, T.; Ito, Y. Formation of Dy-Fe alloy films by molten salt electrochemical process. Electrochim. Acta 2002, 47, 3533-3539. [CrossRef]

24. Kubota, T.; Iida, T.; Nohira, T.; Ito, Y. Formation and phase control of Co-Gd alloy films by molten salt electrochemical process. J. Alloys Compd. 2004, 379, 256-261. [CrossRef]

25. Ding, X. Study of the Mechanism on Formation of Calcium Ferrite in the $\mathrm{Fe}_{2} \mathrm{O}_{3}-\mathrm{CaO}-\mathrm{SiO}_{2}$ System; University of Science and Technology Beijing: Beijing, China, 2015.

26. Xu, Z.Y. Study on Grain Orientation and Low Frequency Electromagnetic Properties of FeSiAl Alloy Absorbents. Bachelor's Thesis, Wuhan University of Technology, Wuhan, China, 2019.

27. Pi, Q.L. Study on Surface Coating Modification of Layered Cathodes Materials $\mathrm{LiNi}_{\mathrm{x}} \mathrm{Co}_{1-\mathrm{x}} \mathrm{O}_{2}$ for Li-ion Batteries. Master's Thesis, Harbin Engineering University, Harbin, China, 2009.

28. Liang, L.; Li, Q.; Qiao, Q.D.; Li, P. Research progress on $\mathrm{LiNiO}_{2}$ cathode material for Li-ion batteries. Inorg. Chem. Ind. 2007, 39, 9-11. [CrossRef]

29. Zhang, N.; Tang, Z.Y.; Huang, Q.H.; Han, B. The Synthesis and Modification of Cathode Material $\mathrm{LiNiO}_{2}$. Chemistry 2005, 068(010), 799. 